\title{
EFFECTS OF RISK MANAGEMENT PRACTICES ON IT PROJECT SUCCESS
}

\author{
Daranee Pimchangthong ${ }^{1}$, Veera Boonjing ${ }^{2}$ \\ ${ }^{1}$ Rajamangala University of Technology Thanyaburi, Faculty of Business Administration, Thailand \\ ${ }^{2}$ King Mongkut's Institute of Technology Ladkrabang, International College \\ Corresponding author: \\ Daranee Pimchangthong \\ Rajamangala University of Technology Thanyaburi \\ Faculty of Business Administration \\ Klong 6, Thanyaburi, Pathum Thani, 12110, Thailand \\ phone: (+66) 890621321 \\ e-mail: Daranee_p@rmutt.ac.th
}

Received: 11 October 2016

Accepted: 2 February 2017

\begin{abstract}
Successful management of an information technology (IT) project is the most desirable for all organisations and stakeholders. Many researchers elaborated that risk management is a key part of project management for any project size. Risk management is so critical because it provides project managers with a forward-looking view of both threats and opportunities to improve the project success. The objectives of this research are to explore organisational factors affecting IT project success and risk management practices influencing IT project success. Risk management practices include risk identification, risk analysis, risk response planning, and risk monitoring and control. The IT project success is measured by process performance and product performance. Data are collected from 200 project managers, IT managers, and IT analysts in IT firms through questionnaires and analysed using Independent Sample t-test, One-way ANOVA, and Multiple Linear Regression at the statistical significance level of 0.05 . The results show that the differences in organisational types affect IT project success in all aspects, while the differences on organisational sizes affect IT project success in the aspect of product performance and total aspects. Risk identification and risk response planning influence the process performance and the total aspects of IT project success. Risk identification has the highest positive influence on product performance, followed closely by risk response, while risk analysis negatively influences product performance.
\end{abstract}

KEYWORDS

risk management, information technology, project success, project management.

\section{Introduction}

Successful IT project management is the most desirable for all organisations and stakeholders. IT project success or failure had long been interesting for researchers over the past 20 years. High failure rates of IT projects were caused by completion beyond budget, behind schedule, and without meeting requirements. Failures could threaten the very existence of the company [1]. The McKinsey Global Institute (MGI) reported that in 2012, on average, large IT projects ran 45 per cent over budget and 7 per cent over time, while delivering 56 per cent less value than predicted. Standish group (2014) reported that only $12 \%$ of projects had fin- ished on time and within the budget. Reference [2] described that " $70 \%$ of software projects fail due to poor requirements with an associated rework spend just north of $\$ 45$ billion annually". Reference [3] elaborated on depressing project failure rates between $50 \%$ and $70 \%$. With these high failure rates, it is not surprising there have been several attempts to reduce those failure rates. Many studies were conducted on the factors related to IT project success. Among several factors, risk management was one of the important factors that affected project success. Reference [4] mentioned that risk management was a key part of project management for any project size. Reference [5] elaborated that risk management was the most important management tool a project 
manager can use to increase the likelihood of project success.

Although there was high importance of risk management to IT project success, the adoption of these risk management methods in practice is inconsistent $[6,7]$. In addition, many project managers decide not to apply any risk management due to financial reasons. This research aims to explore the influence of risk management practices on IT project success. The results from this study can provide guidance on the practical implementation of risk management concerns for IT project success.

\section{Literature review}

\section{Project risk management}

Project risk management is the art and science of identifying, analysing, and responding to risk throughout the life of a project and in the best interests of meeting project objectives [8]. Project risk management involves understanding potential problems that might occur on the project and how they might impede project success. Several research results indicate that poor risk management is a likely cause of project problems and failures. "Risk management is an essential process for the successful delivery of IT projects" $[9,10]$. The body of research examining risk in IT projects spans over 30 years. Risk management researchers have focused on the examination of process models that provide prescriptions for risk management, typically including variations on the four processes of risk identification, assessment, response planning, and monitoring [11]. Reference [8] expresses six processes that involved risk management as follows: planning risk management, risk identification, qualitative risk analysis, quantitative risk analysis, risk response planning, and risk monitoring \& control.

Reference [5] develops a model to investigate the relationship between risk management and IT project success, and the model consists of risk management in four categories: risk identification, risk analysis, risk response planning, and risk monitoring \& control. The research results found that risk identification and risk planning did not influence the subjective performance of the project in terms of reliability, easiness, flexibility, satisfaction and quality. There was no method of risk management that influenced the objective performance of the IT project in terms of cost, schedule, and effort. Therefore, the conclusions couldn't be generalized to all IT companies due to the reduced sample size to an unacceptable error margin. Further research in this field is mandatory to formulate a solid conclusion regard- ing the role and effects of applying risk management in successful IT projects. Reference [12] elaborates that every project had some risk, for example, resources left the organisation, leadership changed, and budgets got cut, etc. There are many factors beyond control. However, many risks to projects can be mitigated or even eliminated with some forethought and ongoing management.

\section{Project success}

The success of IT projects is an area of concern for many organisations around the world. At the beginning, papers on project success were focusing on the classical project triangle, i.e. time, cost, and quality. Later, it was enhanced by considering stakeholder satisfaction and the strategic aspect of the client. This development required the consideration of the interrelationships among the components of the project success: the success criteria and the critical success factors [13]. Besides this triple criterion system, reference [14] discusses the alternative evaluation models such as the key performance indicator (KPI)-based or financial indicator-based, e.g., NPV or IRR evaluation models. These models could be very effective in certain projects, but they may face serious shortcomings when they have to evaluate projects which are hard to quantify. A variety of approaches and models exists on the measurement of project success. One of the most popular models was developed in 1992 [15]. This model expresses six measures for information system's project success as follows: system quality, user satisfaction, information quality, information use, organisational impact, and individual impact. In 2003, reference [16] proposed the updated IS success model. The updated model consisted of six interrelated dimensions of IS success: information, system and service quality, (intention to) use, user satisfaction, and net benefits [16-18]. However, such studies did not touch upon whether and how the delivery project of the IT system had succeeded [19].

In the project perspective, references $[20,21]$ exemplify on success criteria that were measured at the end of the project to judge on its success. Reference [20] is concerned with a broadening of the narrow concept of time, cost, and delivery in accordance with specifications, while reference [21] suggests taking time at the beginning of an IT project to develop and agree on a set of success criteria for each project.

Many researchers suggest that projects should be rated as successful when they are completed within or near the estimated schedule and budget, and produce an acceptable level of performance $[22,23]$. Reference [24] carried out a study using a project com- 
pleted on time and within the budget that worked as the measures to evaluate project success. Some studies were aware of the benefits, which were used as criteria to justify project success [25-27]. References [28-30] use organisational impact and user satisfaction as the criteria to measure the ERP system success. According to reference [31], project success involves two components, e.g., project management success and product success. Project performance is the degree, to which the software project achieves success in the perspectives of process and product [32]. Process performance referred to time and budget, and product performance referred to requirements as shown in Table 1.

Table 1

Dimensions of project performance [5].

\begin{tabular}{|c|c|c|}
\hline $\begin{array}{c}\text { Dimension } \\
\text { of performance }\end{array}$ & Reference [32] & References $[33,34]$ \\
\hline $\begin{array}{c}\text { Process } \\
\text { performance }\end{array}$ & $\begin{array}{l}\text { - Learning } \\
\text { - Process control } \\
\text { - Quality } \\
\text { of interactions }\end{array}$ & $\begin{array}{l}\text { The project was } \\
\text { completed within } \\
\text { - budget } \\
\text { - schedule }\end{array}$ \\
\hline $\begin{array}{c}\text { Product } \\
\text { performance }\end{array}$ & $\begin{array}{l}\text { - Operational } \\
\text { efficiency } \\
\text { - Responsiveness } \\
\text { - Flexibility }\end{array}$ & $\begin{array}{l}\text { The application } \\
\text { developed is } \\
\text { - reliable } \\
\text { - easy to use } \\
\text { - good flexibility } \\
\text { - meets user's } \\
\text { - intended } \\
\text { - functional } \\
\text { - requirements } \\
\text { - satisfied users } \\
\text { - overall high } \\
\text { quality }\end{array}$ \\
\hline
\end{tabular}

\section{Organisational factors}

Organisational factors deal with how far the organisation supported the success of IT project. Several organisational factors affect the success of IT project, e.g. organisational culture, working environment, organisational types, and sizes.

Each organisation has distinctive ways of solving problems, treating employees, passing on the traditions, etc., which are called organisational culture. The organisational culture gives identity to an organisation. Working environment also has a direct impact on the successful IT project. According to reference [35], working environment factors affect the performance of project managers, team relationships, time availability, materials and supplies of projects, and their performance has a direct impact on the success of an IT project.
Several research outputs presented interesting effects of organisational culture on IT project success. Reference [36] expresses that projects required a high degree of organisation and planning to progress smoothly and profitably. The companies must create a collaborative and friendly culture and be willing to change the culture by retaining younger staff and having them to commit to training and development.

Organisation size was one of the important criteria for the success of an IT project in an organisation. SMEs (Small to Medium Enterprise) found that managing successful IT projects was difficult due to the lack of optimum financial resources and a high initial set-up cost [37], while larger firms had an adequate financial and technical capability, and the flexibility to support IT project success. Reference [38] identifies that the major obstacles to IT adoption in small companies are a financial deficiency and insufficient levels of technical capability.

In terms of types, organisations are public and private. A significant difference can be observed between the working environment and organisational culture of a public and private organisation. The differences definitely have a direct impact on the success of the IT project development in an organisation.

The research framework is developed to explore the effect of organisational factors and risk management practices on the success of IT projects as shown in Fig. 1. The framework consists of two independent variables and one dependent variable. The independent variables are organisational factors and risk management practices. The dependent variable is IT project success that includes all dimensions of performance as shown in Table 1. Risk management practices include risk identification, risk analysis, risk response planning, and risk monitoring \& control.

Organizational Factors

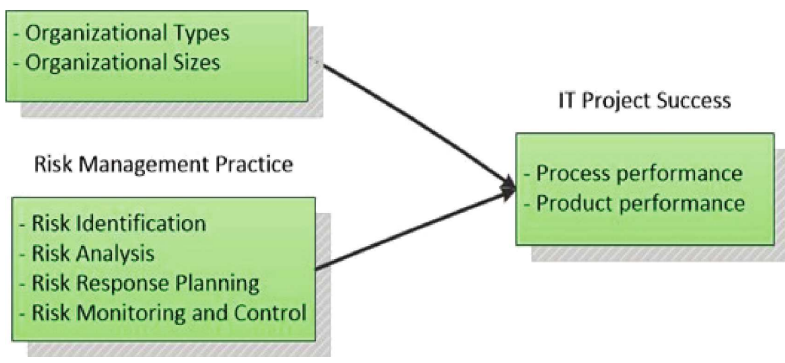

Fig. 1. Research framework.

\section{Research methodology}

This research is a quantitative study of the effects of risk management on IT project success. The objectives of this research are to explore organisational factors affecting IT project success and risk manage- 
ment practices influencing IT project success. Risk management practices include risk identification, risk analysis, risk response planning, and risk monitoring and control. The IT project success was measured by process performance and product performance.

The research involves a literature review, questionnaires, and statistical analysis, both descriptive and inferential statistics, to answer the research questions:

Do organisational factors including organisational types and organisational sizes affect IT project success? Do risk management practices including risk identification, risk analysis, risk response planning, and risk monitoring \& control influence IT project success?

The research hypotheses are:

1. There is a significant difference in organisational factors including organisational types and organisational sizes that affect IT project success.

2. Risk management practices including risk identification, risk analysis, risk response planning, and risk monitoring \& control influence IT project success.

The questionnaire was adopted as a means of collecting reliable and quantifiable data at a reasonable cost. The target population consisted of project managers, IT managers, and IT analysts from IT companies in Thailand and the samples were derived from the convenience sampling method. Questionnaires were distributed to 200 research samples. The questionnaires were categorized into three parts. The first part had two questions about the organisational types and sizes, and they are checklist questions. The second part had 12 questions about the following risk management practices: risk identification, risk analysis, risk response planning, and risk monitoring and control. The third part had ten questions about process performance, which involves budget and time, and product performance, which involves project requirements. The second and third parts of the questionnaire used interval rating scale measurement with five-point Likert-Scale. The Cronbach's alpha value for reliability test of the questionnaires was 0.928. Descriptive statistics for analysing data included frequencies, percentages, means, and standard deviations. Inferential statistics for analysing data included independent samples t-test, one-way ANOVA, and multiple linear regression at the statistical significance level of 0.05 .

\section{Results}

The descriptive statistics results show that most of the organisations that participated in the survey were public $(72 \%)$ and medium size with 100-500 employees (51\%). Measures of central tendency and measures of dispersion were computed to summarize the data and to understand the variability of scores for the organisational type and organisational size variables. The following are the results of this analysis: $\mathrm{N}=200 ; \bar{X}=1.27,2.02 ;$ S.D. $=0.448,0.701$.

Table 2 shows that risk management practices in the aspects of risk identification, risk analysis, and total aspects have a high level of importance $(\bar{X}=3.96,3.55,3.69 ;$ S.D. $=0.644,0.807,0.562)$. The aspects of risk response planning and risk monitoring and control have a moderate level of importance $(\bar{X}=3.49$, 3.32; S.D. $=0.680,0.671)$. IT project success in the aspects of process performance, product performance, and total aspects has a high level of importance $(\bar{X}=4.05,3.91,4.17$; S.D. $=0.788,0.684,0.686)$.

Table 2

Measure of central tendency and dispersion for risk management practices and IT project success.

\begin{tabular}{l|c|c}
\hline & $\bar{X}$ & S.D. \\
\hline Risk management practices & 3.69 & 0.562 \\
\hline 1. Risk identification & 3.96 & 0.644 \\
\hline 2. Risk analysis & 3.55 & 0.807 \\
\hline 3. Risk response planning & 3.49 & 0.680 \\
\hline 4. Risk monitoring and control & 3.32 & 0.671 \\
\hline IT project Success & 4.17 & 0.686 \\
\hline 1. Process performance & 4.05 & 0.788 \\
\hline 2. Product performance & 3.91 & 0.686 \\
\hline
\end{tabular}

Table 3 shows the differences in organisational factors (organisational types and sizes) that affect IT project success in the aspects of process performance, product performance, and total aspects of IT project success. An independent sample t-test is conducted to compare the effect of process performance, product performance and IT project success in a private and public organisation. There are significant differences in a public $(\bar{X}=3.99,4.21,4.29 ;$ S.D. $=0.661$, $0.725,0.655)$ and private organisation $(\bar{X}=3.67$, $3.62,3.84$, S.D. $=0.695,0757,0.660 ; t(198)=2.948$, $5.062,4.359 ; p=0.004,0.000,0.000)$. These results suggest that organisational type does affect process performance, product performance, and IT project success.

One-way ANOVA (F-test) is conducted to compare the effect of organisational size on process performance, product performance and IT project success in a small, medium, and large organisation. There is a significant effect of organisational size on product performance at $p<0.05$ level for the three conditions $[\mathrm{F}(2,197)=4.940 ; p=0.008]$. Post hoc 
Table 3

Differences in organisational factors affecting IT project success.

\begin{tabular}{c|c|c|c}
\hline \multirow{2}{*}{} & \multicolumn{3}{|c}{ Information technology project success } \\
\cline { 2 - 4 } & Process & Product & IT project \\
performance & performance & success \\
\hline Organisational & $\mathrm{t}(198)=2.948$ & $\mathrm{t}(198)=5.062$ & $t(198)=4.359$ \\
types & $p=0.004^{*}$ & $p=0.000^{*}$ & $p=0.000^{*}$ \\
\hline Organisational & - & $\mathrm{F}(2,197)=4.940$ & $\mathrm{~F}(2,197)=4.616$ \\
sizes & - & $p=0.008^{*}$ & $p=0.011^{*}$ \\
\hline
\end{tabular}

* Statistical significance level of 0.05 .

comparisons using Fisher's Least Significant Difference (LSD) test indicate that the mean score for the small organisation condition $(\bar{X}=3.91$, S.D. $=$ $0.830)$ is significantly different from the large organisation condition $(\bar{X}=4.33$, S.D. $=0.792)$. However, the medium size organisation condition $(\bar{X}=3.96$, S.D. $=0.716)$ does not significantly differ from the small and large organisation conditions. Taken together, these results suggest that a large organisation affects product performance.

There is a significant effect of organisational size on IT project success at $p<0.05$ level for the three conditions $[\mathrm{F}(2,197)=4.616 ; p=0.110)]$. Post hoc comparisons using LSD test indicate that the mean score for the small and medium organisation condition $(\bar{X}=4.06,4.09$; S.D. $=0.704,0.638)$ is significantly different from the large organisation condition $(\bar{X}=4.41$, S.D. $=0.686)$. However, the medium size organisation condition $(\bar{X}=4.09$, S.D. $=0.638)$ does not significantly differ from the small organisation conditions. Taken together, these results suggest that a large organisation affects IT project success.

As shown in Table 4, the multiple correlation results demonstrate that dependent variables, which include process performance, product performance, and total aspects of IT project success, have $R$ values of $0.560,0.610$, and 0.597 , respectively, which are interpreted so that the correlations between predictors and dependent variables are rather high in the same direction. The percentages of forecasting equations for process performance, product performance, and total aspects of IT project success are 30.60, 36.20, and 35.00, respectively.

Predictor constants: risk identification, risk analysis, risk response planning, and risk monitoring \& control

The multiple linear regression analysis results show that risk identification $\left(X_{1}\right)$ and risk response planning $\left(X_{3}\right)$ influence process performance at the statistical significance level of 0.05 as shown in Table 5 .

The highest beta coefficient is 0.398 , which means that risk response planning has the greatest influence on predicting process performance, followed closely by risk identification with a beta coefficient of 0.244 .

Results of the multiple linear regression analysis show that risk identification $\left(X_{1}\right)$, risk analysis $\left(X_{2}\right)$, and risk response planning $\left(X_{3}\right)$ influence product performance at the statistical significance level of 0.05 as shown in Table 6 .

Table 4

Multiple correlation between predictors and dependent variables.

\begin{tabular}{c|c|c|c|c}
\hline Model & $\mathrm{R}$ & $\mathrm{R}$ Square & Adjusted R Square & Std. Error of Estimation \\
\hline Process Performance & .560 & .313 & .306 & .57216 \\
\hline Product Performance & .610 & .372 & .362 & .62955 \\
\hline IT Project Success & .596 & .356 & .350 & .55967 \\
\hline
\end{tabular}

Table 5

Multiple regression between predictors and process performance.

\begin{tabular}{c|c|c|c|c|c}
\hline \multirow{2}{*}{ Predictors } & \multicolumn{2}{|c|}{ Unstandar-dized Coeff. } & Standar-dized Coeff. & \multirow{2}{*}{$t$} & \multirow{2}{*}{ Sig. } \\
\cline { 2 - 4 } & $\mathrm{B}$ & Std. Error & Beta & & \\
\hline (Constant) & 1.456 & 0.277 & & 5.257 & $\mathbf{0 . 0 0 0 *}$ \\
\hline Risk Response Planning $\left(X_{3}\right)$ & 0.405 & 0.070 & 0.398 & 5.814 & $\mathbf{0 . 0 0 0 ^ { * }}$ \\
\hline Risk Identification $\left(X_{1}\right)$ & 0.262 & 0.073 & 0.244 & 3.565 & $\mathbf{0 . 0 0 0 *}$ \\
\hline
\end{tabular}

* Statistical significance level of 0.05 . 
Table 6

Multiple regression between predictors and product performance.

\begin{tabular}{|c|c|c|c|c|c|}
\hline \multirow{2}{*}{ Predictors } & \multicolumn{2}{|c|}{ Unstandar-dized Coeff. } & Standar-dized Coeff. & \multirow{2}{*}{$t$} & \multirow{2}{*}{ Sig. } \\
\hline & $\mathrm{B}$ & Std. Error & Beta & & \\
\hline (Constant) & 1.145 & 0.320 & & 3.577 & $0.000^{*}$ \\
\hline Risk Identification $\left(X_{1}\right)$ & 0.471 & 0.082 & 0.383 & 5.767 & $0.000^{*}$ \\
\hline Risk Response Planning $\left(X_{3}\right)$ & 0.428 & 0.079 & 0.367 & 5.419 & $0.000 *$ \\
\hline Risk Analysis $\left(X_{2}\right)$ & -0.131 & 0.060 & -0.135 & -2.189 & $0.030^{*}$ \\
\hline
\end{tabular}

* Statistical significance level of 0.05 .

Table 7

Multiple regression between predictors and IT project success.

\begin{tabular}{|c|c|c|c|c|c|}
\hline \multirow{2}{*}{ Predictors } & \multicolumn{2}{|c|}{ Unstandar-dized Coeff. } & \multirow{2}{*}{$\frac{\text { Standar-dized Coeff. }}{\text { Beta }}$} & \multirow{2}{*}{$t$} & \multirow{2}{*}{ Sig. } \\
\hline & $\mathrm{B}$ & Std. Error & & & \\
\hline (Constant) & 1.430 & 0.271 & & 5.278 & $0.000^{*}$ \\
\hline Risk Identification $\left(X_{1}\right)$ & 0.388 & 0.072 & 0.359 & 5.412 & $0.000^{*}$ \\
\hline Risk Response Planning $\left(X_{3}\right)$ & 0.342 & 0.068 & 0.333 & 5.018 & $0.000^{*}$ \\
\hline
\end{tabular}

The highest beta coefficient is 0.383 , which means that risk identification has the greatest influence on predicting product performance, followed closely by risk response planning and risk analysis with the beta coefficient of 0.367 and -0.135 , respectively.

The multiple linear regression analysis results show that risk identification $\left(X_{1}\right)$ and risk response planning $\left(X_{3}\right)$ influence IT project success at the statistical significance level of 0.05 as shown in Table 7 . The highest beta coefficient is 0.359 , which means risk identification has the greatest influence on predicting IT project success, followed by risk response planning with the beta coefficient of 0.333 .

\section{Conclusions}

The purpose of this article is to explore organisational factors and risk management practices that affect IT project success. To achieve this purpose, the survey research from the sample group provides results that contribute to the development of IT project success. The results demonstrate that the differences in organisational types affect IT project success in all aspects. However, the differences in organisational sizes do not affect IT project success in the aspect of process performance. Risk identification and risk response planning influence the process performance and the success of IT projects. Risk identification has the highest positive influence on product performance, followed closely by risk response, while risk analysis negatively influences on product performance. The results lead to the following implications for the practices:

1. Organisational project types and sizes affect IT project success in the aspect of product perfor- mance. The project manager needs to be sure that all project requirements are well understood by all stakeholders from the early state, which will significantly improve the IT project success rate.

2. A large organisation affects both product performance and IT project success, due to the advantage of having well-organised procedures to perform projects, staff experience, budget, and flexible staff allocation. However, large organisations may still have some drawbacks such as poor agility that may cause some defects in product performance requiring software updates or patches.

3. Process performance is concerned about the completion of the project on time and within the budget, and the results show that the differences in organisational sizes have no effect on process performance. This implies that the finishing of IT projects on time and within the budget was desired by organisations of all sizes.

4. Risk identification practice has the highest influence on product performance and IT project success. The results indicate the importance of risk identification; therefore, it needs to be completed first. The project managers should be aware of this practice to improve IT project success rate.

5. Product performance is positively influenced by risk identification and risk response planning but is negatively influenced by risk analysis. This means that the less risk analysis is performed, the more product performance is expected, or that overanalysing is counterproductive. Organisations need to carefully consider performing risk analysis practices due to time and financial reasons supported by reference [5] that, from the practical point of view, a lot of project managers decide 
not to apply any risk management due to financial reasons.

6. The results indicate the high influences of risk identification and risk response planning practices to IT project success. The results can be helpful to project managers to allocate proper time and resources to perform risk management practices.

In conclusion, all risk management practices including risk identification, risk analysis, risk response planning, and risk monitoring and control are required for process performance, product performance, and IT project success. However, risk analysis practices should be limited to avoid a negative impact on scheduled time and budget.

Although interesting results have been found, the relatively small sample groups were limited to IT projects at IT companies in Thailand. Further research could be conducted internationally on larger sample groups in a variety of industries to obtain more general results.

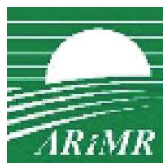

7 th International Conference on Engineering, Project, and Production Management (EPPM2016) was co-organised by the Agency for Restructuring and Modernisation of Agriculture (Poland).

\section{References}

[1] Bloch M., Blumberg S., Laartz J., Delivering large-scale IT projects on time, on budget, and on value, McKinsey \& Company in conjunction with the University of Oxford, available: http://www.mckinsey.com/businessfunctions/business-technology/our-insights/, last accessed 11th February 2016.

[2] Randell A., Spellman E., Ulrich W., Wallk J., Leveraging Business Architecture to Improve Business Requirements Analysis, Business Architecture Guild Whitepaper 2014.

[3] Jenner S., Why do projects 'fail' and more to the point what can we do about it? The case for disciplined, 'fast and frugal' decision-making, PM World Journal, 5, 3, 2015.

[4] Lavinson M., IT Project Management: 10 LessConsidered Keys to Success, 2010, available: http://www.cio. com/article/2417296.

[5] Didagra O., The Role and the Effects of Risk Management in IT Projects Success, Informatica Economică, 17, 1, 2013.

[6] Bannerman P.L., Risk and Risk Management in Software Projects: A reassessment, Journal of Systems and Software 81, 12, 2118-2133 2008.
[7] Taylor H., Artman E., Woelfer J.P., Information Technology Project Risk Management: Bridging the Gap between Research and Practice, Journal of Inform Technology, 27, 17-34, 2012.

[8] Schwalbe K., Information Technology Project Management 7th, Course Technology, Cengage Learning 440-446, 2014.

[9] Baccarini D., Salm G., Love P.E.D., Management of risks in information technology projects, Industrial Management \& Data Systems, 104, 4, 286-295, 2004.

[10] Alhawari S., Karadech L., Talet N.A., Mansour E., Knowledge-based risk management framework for information technology project, International Journal of Information Management, 32, 1, 50-65, 2012.

[11] Taylor H., Artman E., Woelfer J.P., Information technology project risk management: bridging the gap between research and practice, Journal of Information Technology, 27, 17-34, 2012.

[12] Crader B., What makes an IT Project Successful? Nonprofit Edition, NpENGAGE, available: http://npengage.com/ nonprofit-technology/whatmakes-project-successful-nonprofit-edition/, last accessed 5th May 2015.

[13] Judgev K., Müller R., A Retrospective Look at Our Evolving Understanging of Project Success, Project Managament Journal, 36, 4, 19-31, 2005.

[14] Blaskovics B., The Impact of Project Manager on Project Success: The case of ICT sector, Society and Economy, 38, 2, 261-281, 2016.

[15] DeLone W.H., McLean E.R., Information Systems Success: The Quest for the Dependent Variable, Information Systems Research, 3, 1, 60-95, 1992.

[16] DeLone W.H., McLean E.R., The DeLone and McLean Model of Information Systems Success: A Ten-Year Update, Journal of Management Information Systems, 19, 4, 9-30, 2003.

[17] DeLone W.H., McLean E.R., Measuring E-Commerce Success: Applying the DeLone 8 McLean Information Systems Success Model, International Journal of Electronic Commerce, 9, 1, 31-47, 2004.

[18] Sudhakar G. P., A model of critical success factors for software projects, Enterprise Information Manage-ment 25, 6, 537-558, 2012.

[19] Müller R., Martinsuo M., The impact of relational norms on information technology project success and its moderation through project governance, International Journal of Managing Projects in Business, 8, 1, 176-154, 2015.

[20] Atkinson R., Project management: cost, time and quality, two best guesses and a phenomenon it's time 
to accept other success criteria, International Journal of Project Management, 17, 4, 337-343, 1999.

[21] Wateridge J., How can IS/IT projects be measured for success?, International Journal of Project Management, 16, 1, 59-63, 1998.

[22] Project Management Institute $A$ Guide to the Project Management Body of Knowledge, 3rd ed., Newtown Square, Pennsylvania, 2003.

[23] Martin N.L., Pearson J.M., Furumo K., IS Project management: Size, Practices and Project Management Office, Journal of Computer Information Systems, 47, 4, 52-60, 2007.

[24] Mahaney R.C., Lederer A.L., An Agency Theory Explanation of Project Success, The Journal of Computer Information Systems, 51, 4, 102-113, 2011.

[25] Iacovou C.L., Benbasat I., Dexter A.S., Electronic data interchange and small organizations: adoption and impact of technology, MIS Quarterly, 19, 4, 465485, 1995.

[26] Nelson R., Project retrospectives: evaluating project success, failure and everything in between, MIS Quarterly Executive, 4, 3, 361-372, 2005.

[27] Peppard J., Ward J.M., Daniel E.M., Managing the realization of business benefits from IT investments, MIS Quarterly Executive, 6, 1, 1-11 2007.

[28] Gable G.G., Sedera D., Chan T., Re-conceptualizing information system success: the IS impact measurement model, Journal of the Association for Information System, 9, 7, 377-408, 2008.

[29] Jones M.C., Zmud R.W., Clark T.D., ERP in practice: a snapshot of post installation perception and behaviors, Communications of the Association for Information Systems, 23, 437-462, 2008.
[30] Ward J., Daniel E.M., The role of project management offices (PMOs) in IS project success and management satisfaction, Journal of Enterprise Information Management, 26, 3, 316-336, 2013.

[31] Baccarini D., The logical Framework Method for Defining Project Success, Project Management Journal, 30, 4, 25-32, 1999.

[32] Nidumolu S., Standardization, Requirements Uncertainty and Software Project Performance, Information and Management, 31, 3, 135-150, 1996.

[33] Jun L., Qiuzhen W., Qingguo M., The effects of project uncertainty and risk management on IS development project performance: A vendor perspective, International Journal of Project Management, 29, 923-933, 2011.

[34] Wallace L., Keil M., Arun R., How software project risk affects project performance: an investigation of the dimensions of risk and an exploratory model, Decision Sciences, 35, 2, 289-321, 2004.

[35] Pheng L.S., Chuan Q.T., Environmental factors andwork performance of project managers in the construction industry, International Journal of Project Managemant, 24, 24-37, 2006.

[36] Allen M., Alleyne D., Farmer C., McRae A., Turner C., A Framework for Project Success, Journal of Information Technology and Economic Development, $5,2,1-17,2014$.

[37] Dixon T., Pottinger G., Jordan A., Lessons from the private finance initiative projects in the UK: Benefits, problems and critical success factors, Journal of Property Invest. Finance, 23, 5, 412-423, 2005.

[38] Cragg P., King M., Small-firm computing: motivators and inhibitors, MIS Quarterly, 17, 1, 47-53, 1993. 